the desperation from a downtime situation.

Great Neck Library is also planning to use the Apples for other functions, which, it is hoped, will be implemented soon.

\section{Multimedia Catalog: COM and Online}

\author{
Kenneth J. BIERMAN: Tucson Public Li- \\ brary, Tucson, Arizona.
}

Like many public libraries, the Tucson Public Library (TPL) is closing its card catalog and implementing a vendorsupplied microform catalog. Unlike most of these other libraries, however, the TPL microform catalog will not include location or holding information. The indication of where copies of a particular title are actually available (i.e., which of the fifteen possible branch locations) will be available only by accessing a video display terminal connected to the online circulation and inventory control system.

Conceptually, the TPL catalog will be in two parts with each part intended to serve different functions. ${ }^{1}$ The microform catalog (copies available in both film and fiche format) will fulfill the bibliographic function of the catalog. This catalog will contain bibliographic description and provide the traditional access points of author, title, and subject. The online catalog (online terminals are in place at all reference desks and a few public access terminals will also be available) will fulfill the finding or locating function of the catalog. This catalog will contain very brief bibliographic description and will only be searchable by author, title, author/title, and call number, and will contain the current status of every copy of every title in the library system (i.e., on shelf, checked out, at bindery, reported missing, etc.).

Why did the Tucson Public Library make this decision? There are two major reasons:

1. Accuracy. The location information, if provided in the microform catalog, would always be inaccurate and out of date. Assuming that the locations listed in the latest edition of the mi- croform catalog were completely accurate when the catalog was first issued (an unrealistic assumption to begin with as anyone who has ever worked with location information at a public library with many branches well knows!), the location information would become increasingly less accurate with each day because of the large number of withdrawals, transfers, and added copy transactions that occur (more than 100,000 a year). In addition, at any given time, one-quarter to one-third of the materials in busy branches are not on the shelf because they are either checked out or waiting to be reshelved. Thus, the microform catalog would indicate that these materials were available at specific branches when a significant percentage would in fact not be available at any given time. In short, even in the best of circumstances, easily half of the location information would be incorrect in telling a user where a copy of a title was actually available at that moment.

2. Cost. A study done at the Tucson Public Library indicated that close to half of the staff time of the cataloging department was spent dealing with location and holding information. This time includes handling transfers, withdrawals, and added copies. All of this record keeping is already being done as a part of the online circulation and inventory control system (the Tucson Public Library has no card shelflist containing copy and location information but rather relies completely on the online file for this type of information). To "duplicate" the information in the microform catalog would cost an estimated $\$ 40,000$ to $\$ 60,000$ a year and the information in the microform catalog would never be accurate or up to date for the reasons outlined above.

Figure 1 is a brief summary of how the bibliographic system will work.

Would the system in figure 1 be improved if holdings were included in the microform catalog? On the surface, the obvious answer is yes-more information is 
KNOWN-ITEM SEARCH

(37 percent of TPL catalog use according to catalog use survey conducted at the TPL in 1971)

\section{SUBJECT SEARCH}

(63 percent of TPL catalog use by public according to catalog use survey conducted at the TPL in 1971)
User searches microform catalog by author and/or title.

If user does not find desired bibliographic entry, user either leaves unsatisfied or goes to desk (or public access terminal) for help.

If user finds the desired bibliographic entry, he/she writes down call number (or author for fiction) and proceeds to shelf.

If user finds book on shelf he/she checks it out.

If user does not find book on shelf, user either leaves unsatisfied or goes to desk (or public access terminal) to obtain holdings information or ask for help (put on reserve, borrow from another library, possible purchase of additional copies, etc.).

User searches microform catalog.

User writes down call number(s) and proceeds to shelf.

If user finds appropriate material(s), he/she checks it out.

If user does not find appropriate material he/she leaves unsatisfied or goes to desk for help (reference interview, etc.).

Fig. 1. Summary of How System Will Work.

always better. But, if we examine the situation in depth, perhaps not. Let us look at some hypothetical situations.

If the user is doing a search and does not find the desired entry/entries in the microform catalog, it makes no difference whether holdings are included in the catalog. The user will still either leave unsatisfied or go to the desk for help.

If the user is doing a known-item search and finds the desired item and notes, and the agency he/she is at is listed as a holding agency, he/she will proceed to the shelf. If the desired material is found, fine. If not (because the material is checked out, reported missing, or withdrawn), he/she will either leave unsatisfied or go to the desk (or public access terminal) for help.

If the user is doing a known-item search and finds the desired item in the microform catalog but notes that the agency is not listed as a holding agency, what are his/her choices? The user can go away unsatisfied without checking the shelves (although there may be a copy on the shelf because a copy may have been added to that agency since the microform catalog was last recumulated) or he/she can go to the desk (or public access terminal) to obtain help; here he/she will have access to the "real" holdings information-on the online system. The user could notice from the holdings in the microform catalog that another branch has the item and drive to the other branch. However, when the user gets there he/she may discover that the item is not available-information that could have been found in the online system at the original branch if he/she had gone to the desk (or public access terminal).

The purpose of the above exercise is to demonstrate that in all cases the user is still going to require access to the online catalog in order to determine holdings more accurately. With time, this access will become increasingly self-service through public access terminals. From the user's point of view, providing inaccurate holdings in the microform catalog does very little good and can actually do harm by leaving the impression that, if a library is listed as a holding library, that library will have the item (a false conclusion because of checkouts, reported missings, and withdrawals) or leaving the impression that if a library is not listed as a holding library, that library will not have the item (a false conclusion because a copy could have been added recently but that fact is not yet reflected in the microform catalog).

If the user is doing a subject search, holdings are of less value in the catalog 
anyway because he is primarily getting suggested classification numbers in order to browse.

The Tucson Public Library could not have made the above decisions if it did not have a complete online file of all its holdings (including even reference materials that never circulate). But since this data did exist (after a five-year bar-coding effort) and since more than forty online terminals were already in place throughout the library system to access the online file, the decision not to include locations or holdings in the microform catalog seemed reasonable. In the longer-range future (1990?), it is very likely that the entire catalog will be available online. In the meantime, the Tucson Public Library did not want to divide its resources maintaining two location records, but rather wanted to concentrate resources in maintaining one accurate record of locations available as widely as possible throughout the library system (by installing more online terminals for staff and public use). Was this decision a sound one? We don't know. The microform catalog has not yet been introduced for public use. By the end of this year we should have some preliminary answers to this question.

\section{REFERENCES}

1. Robin W. MacDonald and J. McRee Elrod, "An Approach to Developing Computer Catalogs," College \& Research Libraries 34:202-8 (May 1973).

\section{A Structure Code for Machine Readable Library Catalog Record Formats}

\section{Herbert H. HOFFMAN: Santa Ana College, Santa Ana, California.}

Libraries house many types of publications in many media, mostly print on paper, but also pictures on paper, print and pictures on film, recorded sound on plastic discs, and others. These publications are of interest to people because they contain recorded information. More precisely said, because they contain units of intellectual, artistic, or scholarly creation that collec- tively can be called "works."

One could say simply that library materials consist of documents that are stored and cataloged because they contain works. The structure of publications into documents (or "books") and works, the clear distinction between the concept of the information container as opposed to the contents, deserves more attention than it has received so far from bibliographers and librarians.

The importance of the distinction between books and works has been hinted at by several theoreticians, notably Lubetzky. However, the idea was never fully developed. The cataloging implications of the structural diversity among documents were left unexplored. As a consequence, librarians have never disentangled the two terms book and work. From the Paris principles and the MARC formats to the new second edition of the Anglo-American Cataloguing Rules, the terms book and work are used loosely and interchangeably, now meaning a book, now a work proper, now part of a work, now a group of books.

Such ambiguity can be tolerated as long as each person involved knows at each step which definition is appropriate when the term comes up. But as libraries ease into the age of electronic utilities and computerized catalogs based on records read by machine rather than interpreted by humans, a considerably greater measure of precision will have to be introduced into library work. As one step toward that goal an examination of the structure of publications will be in order.

The items that are housed in libraries, regardless of medium, are of two types. They are either single documents, or they are groups of two or more documents. Items that contain two or more documents are either finite items (all published at once, or with a first and a last volume identified) or they are infinite items (periodicals, intended to be continued indefinitely at intervals). Schematically, these three types of bibliographic items in libraries can be represented as shown in figure 1 .

It should be noted that all publications, all documents, all bibliographic items in li- 